\title{
Anchor-Shaped Design of a Submerged Entry Nozzle for the Continuous Casting of Steel
}

\author{
Carlos A. Hernandez1, Miguel A. Barron', Raul Miranda2 \\ ${ }^{1}$ Departamento de Materiales, Universidad Autonoma Metropolitana Azcapotzalco, Mexico City, Mexico \\ ${ }^{2}$ Departamento de Electronica, Universidad Autonoma Metropolitana Azcapotzalco, Mexico City, Mexico \\ Email:bmma@correo.azc.uam.mx
}

How to cite this paper: Hernandez, C.A., Barron, M.A. and Miranda, R. (2016) Anchor-Shaped Design of a Submerged Entry Nozzle for the Continuous Casting of Steel. Open Journal of Applied Sciences, 6, 593 600.

http://dx.doi.org/10.4236/ojapps.2016.69058

Received: August 9, 2016

Accepted: September 3, 2016

Published: September 6, 2016

Copyright $\odot 2016$ by authors and Scientific Research Publishing Inc. This work is licensed under the Creative Commons Attribution International License (CC BY 4.0).

http://creativecommons.org/licenses/by/4.0/

\begin{abstract}
An anchor-shaped geometrical design for a Submerged Entry Nozzle for the slab continuous casting of steel is presented in this work. To evaluate its performance, transient 3D multiphase numerical simulations were carried out using the Computational Fluid Dynamics technique. The performance of the proposed nozzle is numerically compared with that of a conventional cylindrical nozzle. Computer results show that the chance of formation of Karman's vortexes and powder entrapment becomes small for the anchor-shaped SEN.
\end{abstract}

\section{Keywords}

Anchor-Shaped SEN, Computational Fluid Dynamics, Continuous Casting, Numerical Simulations, Slab Casting, Submerged Entry Nozzle

\section{Introduction}

Nowadays, around $95 \%$ of the world raw steel is cast by means of the continuous casting process [1]. The quality of the steel slabs is greatly influenced by the fluid flow in the continuous casting mold [2], and the geometry of the Submerged Entry Nozzle (SEN) is the most important parameter [3] [4]. In the continuous casting mold, mold powder is added in order to prevent heat losses, provide good lubrication, and protect the molten steel from air oxidation. However, sometimes the mold powder is entrapped into the molten steel, and this entrapment deteriorates the quality of the solid steel [5].

Formation of Karman's vortexes on the meniscus of the mold is promoted by improper designs of the SEN. These vortexes cause powder entrapment and macro inclusions in the steel products [5]-[7]. The design of the SEN aims to minimize instabilities of the free surface to prevent the Karman's vortexes. An elliptic SEN is proposed in [8]. In accordance to their authors, this design reduces the pressure difference around the nozzle, 
avoiding powder entrapment. In [9] the transient flow inside a bifurcated SEN is physically and numerically studied. It is reported that the flow pattern inside the SEN is periodic in nature. The multiple frequencies are determined from the power spectrum of the numerically generated time series. In [10], the effect of the configuration parameters of the SEN in the flow field in a slab mold is analyzed by means of water modeling. The design of a swirling-flow SEN is proposed in [11]. Its performance is evaluated through water modeling. This SEN supposedly allows an increase of the casting speed without affecting the surface quality of solidified steel. In [12] it is analyzed the optimization of the molten steel flow in the mold by changes in the port design of the SEN.

An anchor-shaped design for a SEN for the slab continuous casting of steel is presented here. Its performance is evaluated by means of mathematical modeling. Transient 3D numerical simulations are carried out using the Computational Fluid Dynamics (CFD) technique. The performance of the proposed SEN is compared with that of a conventional cylindrical SEN.

\section{Design of the Anchor-Shaped SEN}

The geometry of the considered two-port anchor-shaped SEN is shown in Figure 1. The SEN dimensions are as follows: height $=0.5 \mathrm{~m}$, arm-span $=0.40 \mathrm{~m}$, plate thickness at arm tips $=0.02 \mathrm{~m}$, inlet diameter $=0.06 \mathrm{~m}$, exit port diameter $=0.04 \mathrm{~m}$, wall thickness $=$

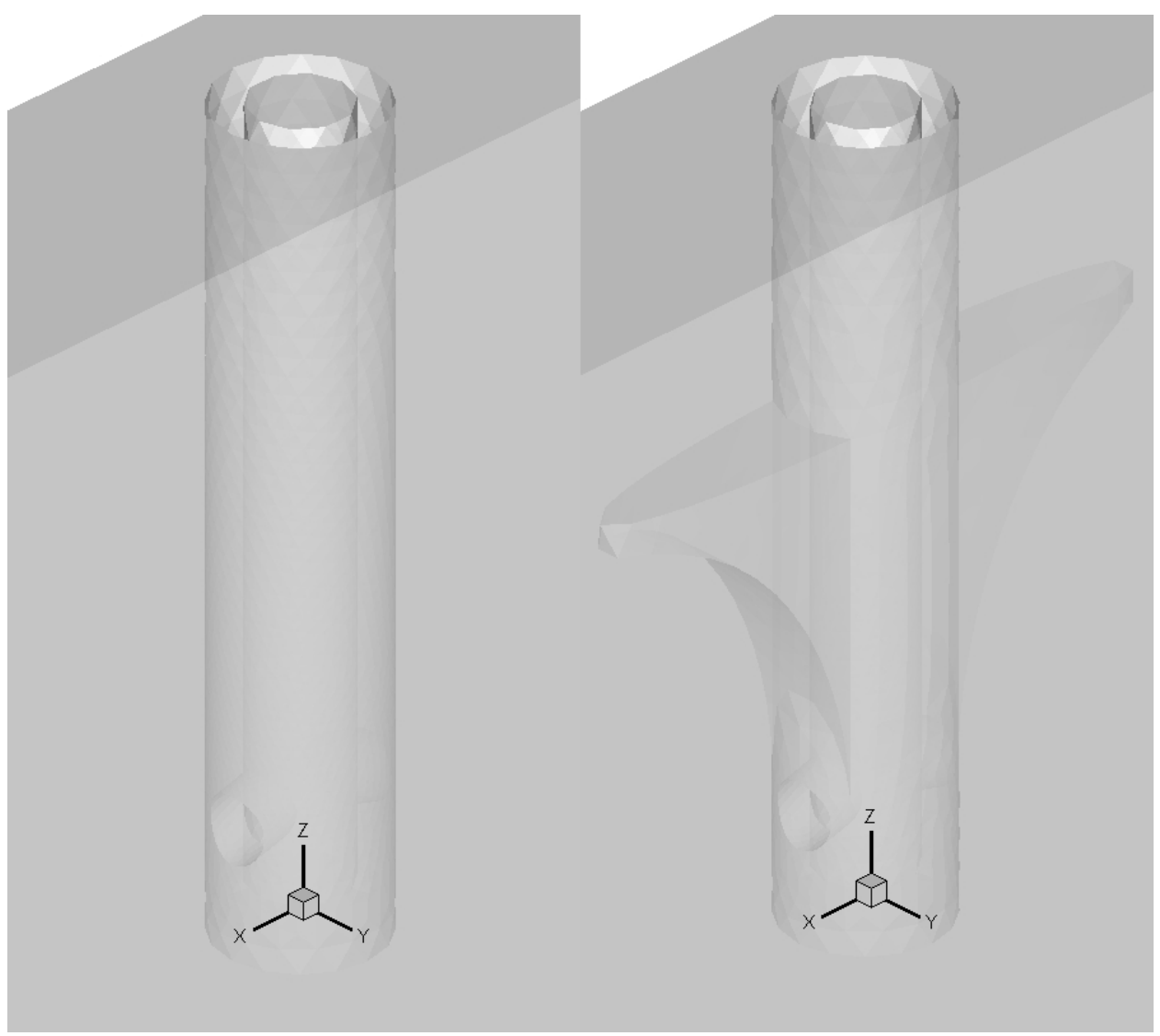

Figure 1. The conventional cylindrical SEN (left) and the anchor-shaped SEN (right). 
$0.01 \mathrm{~m}$, pool height $=0.05 \mathrm{~m}$, discharge angle $=12$ degrees to the horizontal

\section{Mathematical Model}

The flow of an isothermal incompressible Newtonian fluid and the mass conservation are represented by the Navier-Stokes equations and the continuity equation [13]. Both equations come from force balances and mass conservation, respectively:

$$
\frac{\partial\left(\rho u_{i}\right)}{\partial t}+\frac{\partial\left(\rho u_{i} u_{j}\right)}{\partial x_{j}}=-\frac{\partial p}{\partial x_{i}}+\frac{\partial}{\partial x_{j}}\left\{\mu_{e f f}\left(\frac{\partial u_{i}}{\partial x_{j}}+\frac{\partial u_{j}}{\partial x_{i}}\right)\right\}
$$

where $\rho$ is the fluid density; $u_{i}$ is the $I^{\text {th }}$ component of the fluid velocity $u$; $t$ is time; $x_{j}$ is $j$ spatial coordinate; $p$ is pressure; and $\mu_{\text {eff }}$ is the effective fluid viscosity. To maintain the mass balance in the system, the continuity equation $\partial u_{j} / \partial x_{j}=0$ must be solved. Turbulence is simulated by means of the classical two equations $K$ - $\varepsilon$ model [14]:

$$
\begin{gathered}
\rho v_{j} \frac{\partial K}{\partial x_{j}}=\frac{\partial}{\partial x_{j}}\left(\frac{\mu_{t}}{\sigma_{K}} \frac{\partial K}{\partial x_{j}}\right)+\mu_{t} \frac{\partial v_{j}}{\partial x_{i}}\left(\frac{\partial v_{i}}{\partial x_{j}}+\frac{\partial v_{j}}{\partial x_{i}}\right)-\rho \varepsilon \\
\rho v_{j} \frac{\partial \varepsilon}{\partial x_{j}}=\frac{\partial}{\partial x_{j}}\left(\frac{\mu_{t}}{\sigma_{\varepsilon}} \frac{\partial \varepsilon}{\partial x_{j}}\right)+C_{1} \mu_{t} \frac{\varepsilon}{K} \frac{\partial v_{j}}{\partial x_{i}}\left(\frac{\partial v_{i}}{\partial x_{j}}+\frac{\partial v_{j}}{\partial x_{i}}\right)-C_{2} \frac{\varepsilon}{K} \rho \varepsilon
\end{gathered}
$$

The effective viscosity $\mu_{\text {eff }}$ of Equation (1) is determined from the expression $\mu_{\text {eff }}=\mu_{0}+\mu_{t}$, where $\mu_{0}$ is the laminar viscosity and $\mu_{t}$ is the turbulent viscosity. On the other hand, $\mu_{t}$ is obtained from the expression $\mu_{t}=\rho C_{\mu} K^{2} / \varepsilon$, where $K$ and $\varepsilon$ are calculated from Equation (2) and Equation (3). Besides, the values of $\sigma_{K}, \sigma_{\varepsilon}, C_{1}, C_{2}$ and $C_{\mu}$ are $1.0,1.3,1.44,1.92$ and 0.09 , respectively [14]. Boundary conditions for $K$ and $\varepsilon$ at the inlet nozzle is calculated from $K_{i n}=0.01 U_{i n}^{2}$ and $\varepsilon_{i n}=2 K_{i n}^{3 / 2} / D_{n}$ [15] where $U_{i n}$ and $D_{n}$ are the inlet nominal velocity and the nozzle diameter, respectively. The Pressure-Implicit with Splitting of Operators (PISO) algorithm was employed for the pressure-velocity coupling.

The Volume of Fluid (VOF) model is employed to issue the multiphase flow. VOF is based on the assumption that two or more phases are not interpenetrating [16]. For each additional phase $q$ its volume fraction $\alpha_{q}$ is introduced as a variable. In each control volume the volume fractions of all phases sum to unity. The tracking of the interface between the phases is accomplished by solving the continuity equation for each phase [16] [17]:

$$
\frac{\partial \alpha_{q}}{\partial t}+\vec{v} \cdot \nabla \alpha_{q}=0
$$

\section{Numerical Solution}

To analyze the performance of the conventional and anchor-shaped SEN, transient 3-D two-phase (air, molten steel) isothermal computer simulations were carried out using a time step of $0.001 \mathrm{~s}$. This time step value was determined from numerical experiments, and corresponds to the maximum value which still provides numerical stability. Computer runs of $90 \mathrm{~s}$ of integration time were considered to obtain a well developed mol- 
ten steel flow in the mold. The mold dimensions were as follows: height, $2 \mathrm{~m}$; width, 0.6 $\mathrm{m}$; thickness, $0.2 \mathrm{~m}$. The initial level of molten steel was $1.82 \mathrm{~m}$, the remaining volume of the mold was air. The physical properties of molten steel were as follows: density, $7100 \mathrm{~kg} / \mathrm{m}^{3}$; viscosity, $0.0067 \mathrm{~kg} /(\mathrm{m} . \mathrm{s})$. Boundary conditions were as follows: velocity inlet $2.83 \mathrm{~m} / \mathrm{s}$, which corresponds to a casting speed of $1.5 \mathrm{~m} / \mathrm{min}$; turbulent kinetic energy $0.08 \mathrm{~m}^{2} / \mathrm{s}^{2}$, turbulent dissipation rate $0.755 \mathrm{~m}^{2} / \mathrm{s}^{3}$. The computational mesh employed in the computer simulations is shown in Figure 2. This mesh contains 464,000 tetrahedral/hybrid cells.

\section{Results and Discussion}

Figure 3 shows the phase distribution and the velocity vectors for the conventional cylindrical SEN (left) and the anchor-shaped SEN (right) for the vertical plane with Y $=0$. An elapsed time of $90 \mathrm{~s}$ is chosen. The cylindrical SEN exhibits a deeper depression of the free surface and larger magnitude of the velocity vectors in the upper section of the mold than the anchor-shaped SEN. This means that the cylindrical SEN is prone to generate Karman's vortexes on the meniscus of the mold. Therefore, the chance of powder entrapment and capturing of macro inclusions is greater for the conventional SEN than for the anchor-shaped one.

Figure 4 shows a magnification of Figure 3 in the vicinity of each SEN. The magnitude

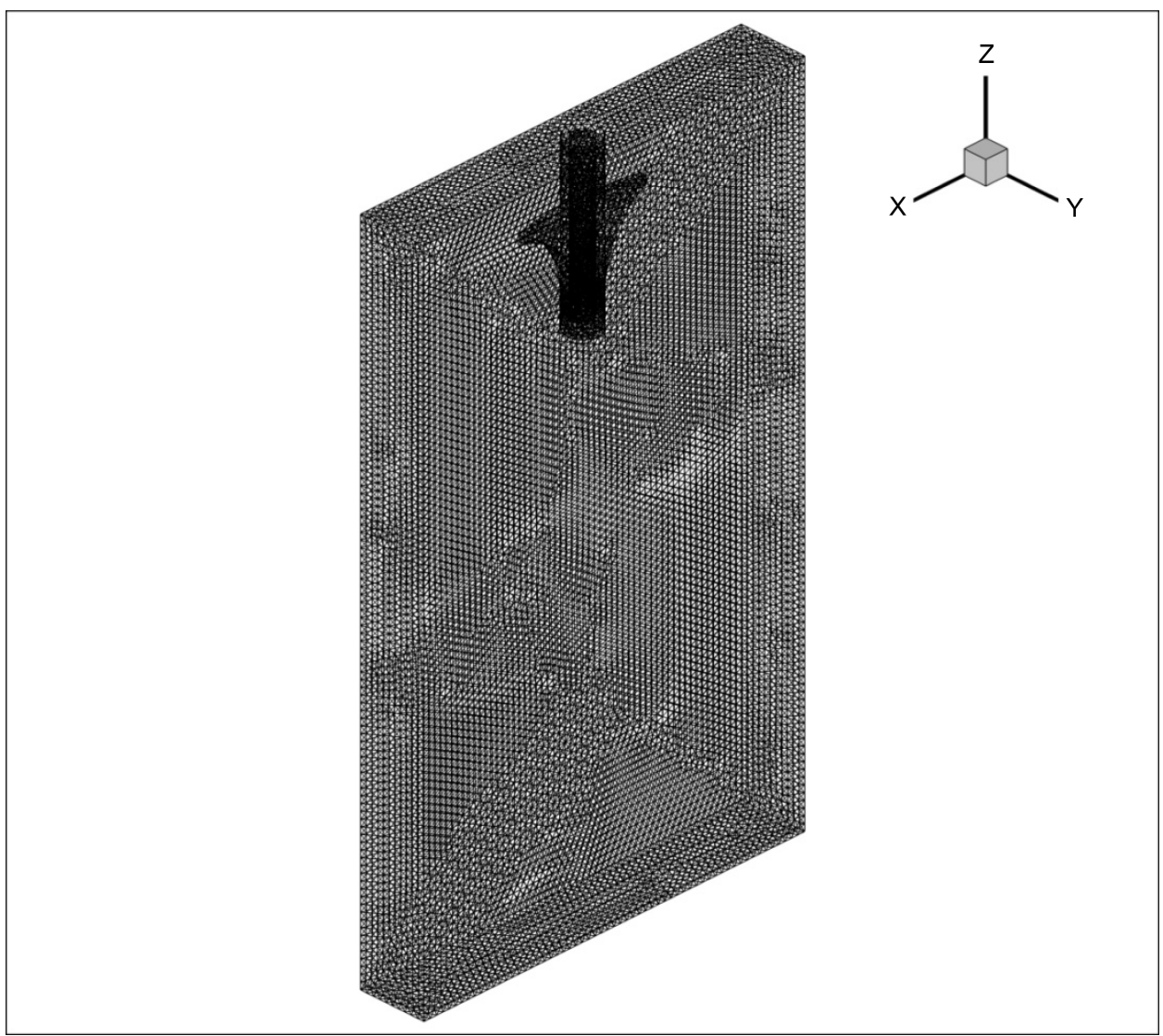

Figure 2. The continuous casting mold and the computational mesh employed. 

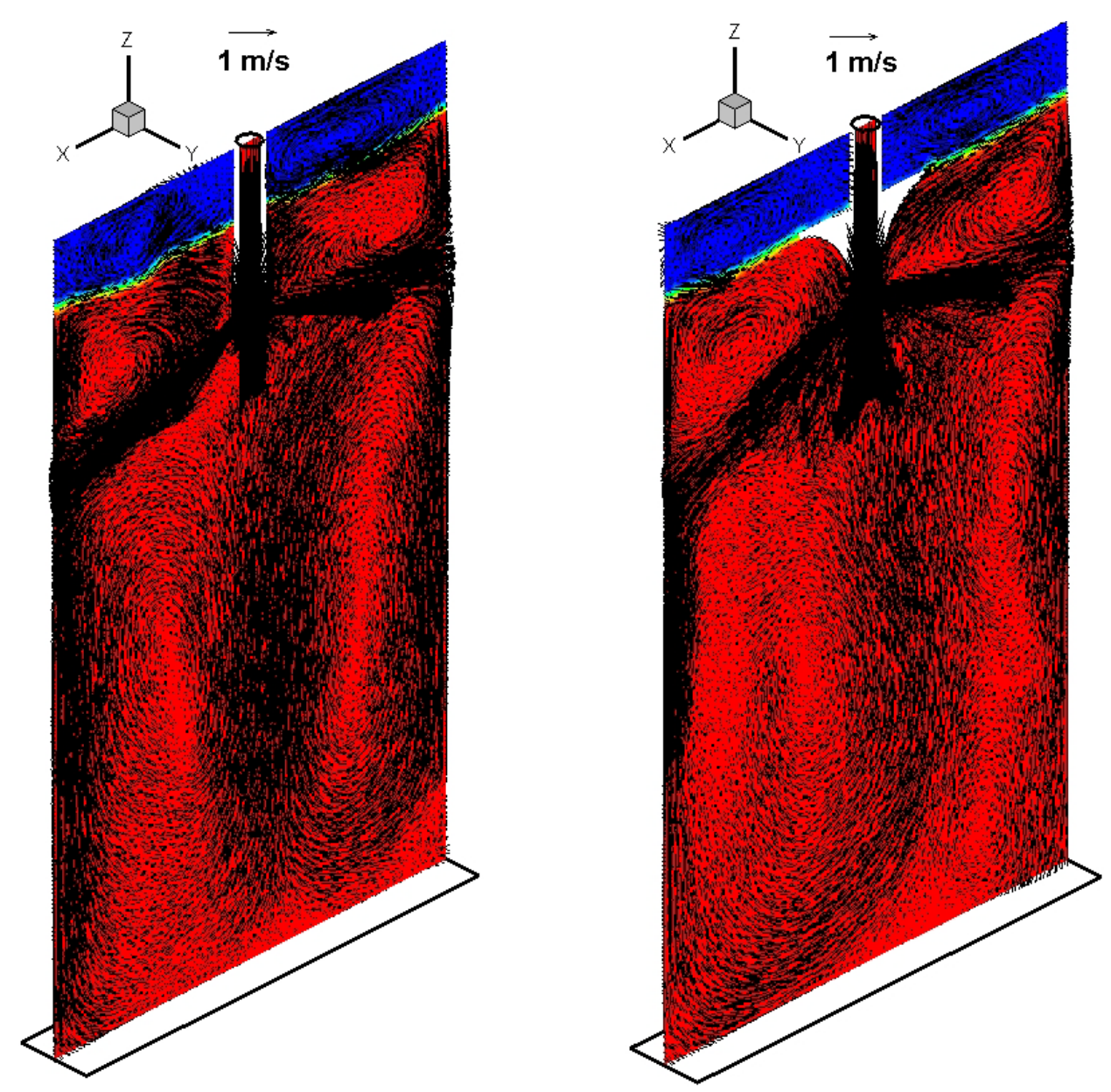

Figure 3. Phase distribution and velocity vectors for the conventional cylindrical SEN (left) and the anchor-shaped SEN (right) in the vertical plane $\mathrm{Y}=0$. Red phase is molten steel, blue phase is air. Elapsed time $=90 \mathrm{~s}$.

of the velocity vectors around the anchor-shaped SEN is significantly smaller than the case of the cylindrical SEN. This phenomenon is due to the presence of the solid arms of the anchor-shaped SEN which act as physical barriers to the flow of molten steel.

Figure 5 depicts the velocity vectors in the horizontal plane for $\mathrm{Z}=0.8$. The plane $\mathrm{Z}=$ 0.8 is important given that is very close to the free surface of the mold, where the Karman's vortexes are formed. Two recirculation zones are observed on the left side of the cylindrical SEN. Besides, a downward flow of molten steel is appreciated on the right side of this SEN. The anchor-shaped SEN shows a homogeneous flow on both sides of the plane. This indicates that the probability of Karman's vortexes formation and powder entrapment is lower than for the cylindrical SEN.

Finally, Figure 6 shows the evolution of the average velocity magnitude in the mold as time proceeds from the beginning of the cast where the molten steel is motionless. This figure was obtained through averaging the molten steel velocity in the mold for different elapsed time intervals. Until $60 \mathrm{~s}$ of time has elapsed, the behavior of both SEN is analogous. However, from this time the anchor-shaped SEN presents a lower average 


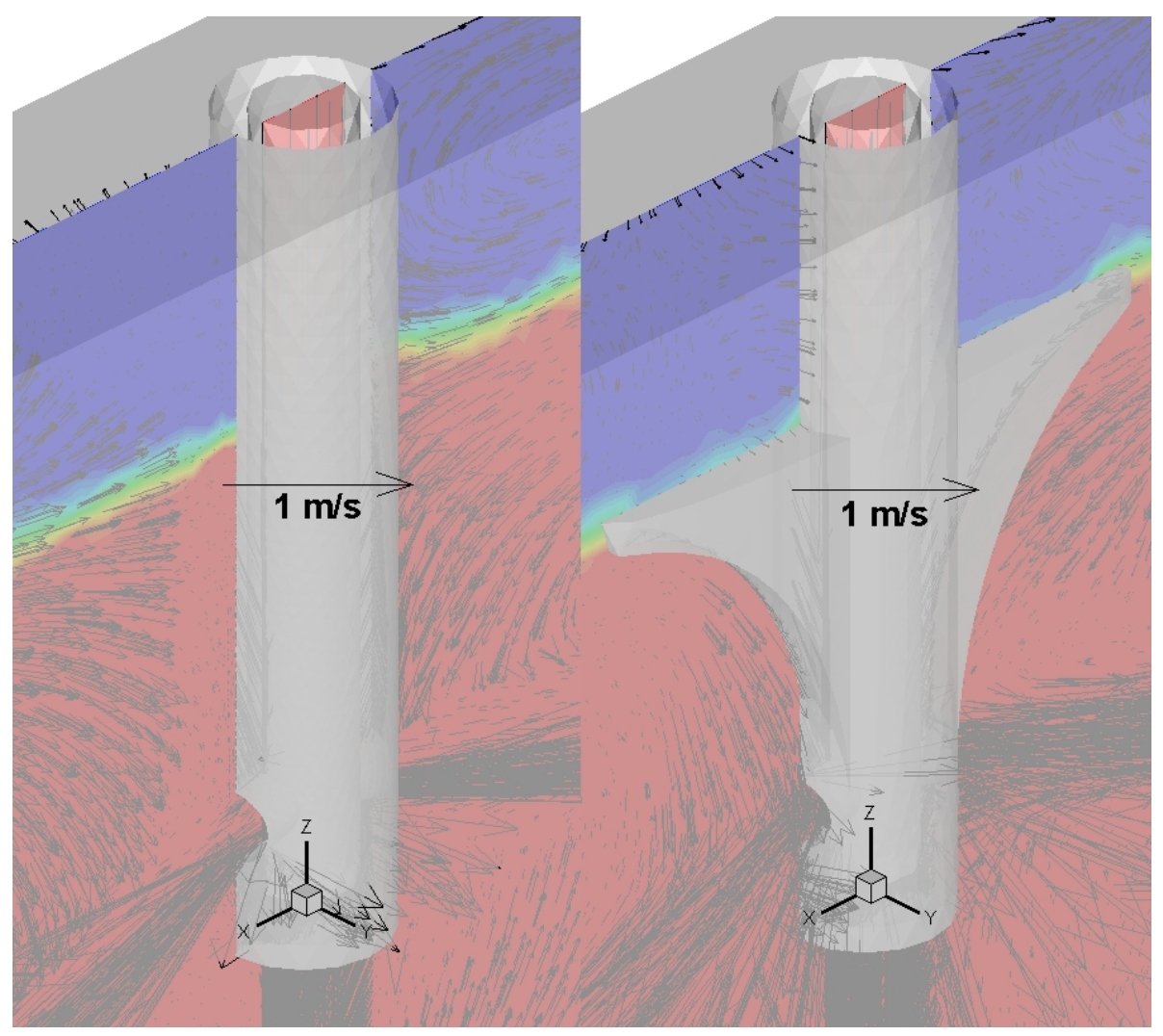

Figure 4. Magnification of Figure 3 in the vicinity of each SEN.

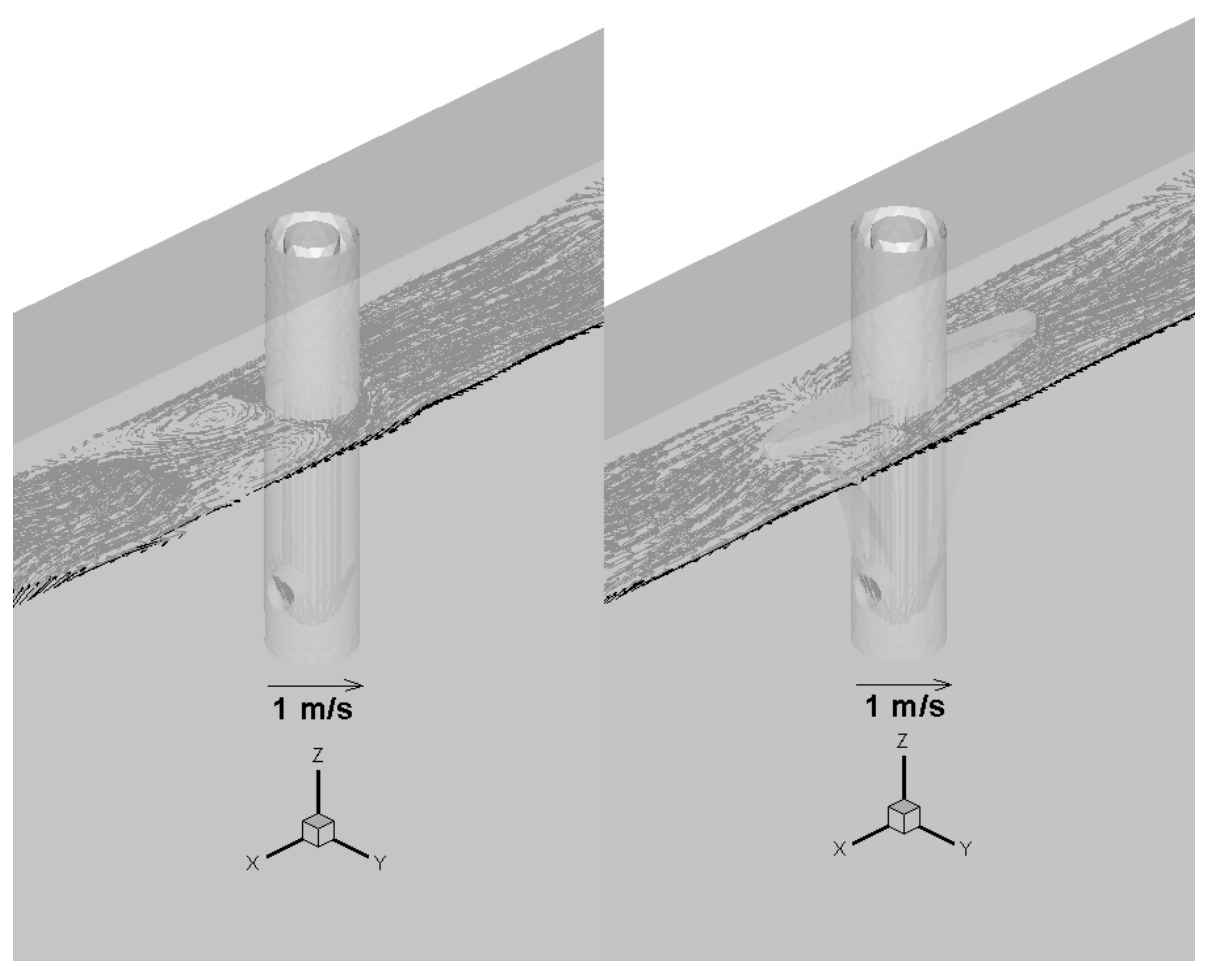

Figure 5. Velocity vectors in the horizontal plane $\mathrm{Z}=0.8$, close to the free surface. Cylindrical SEN (left), anchor-shaped SEN (right). 


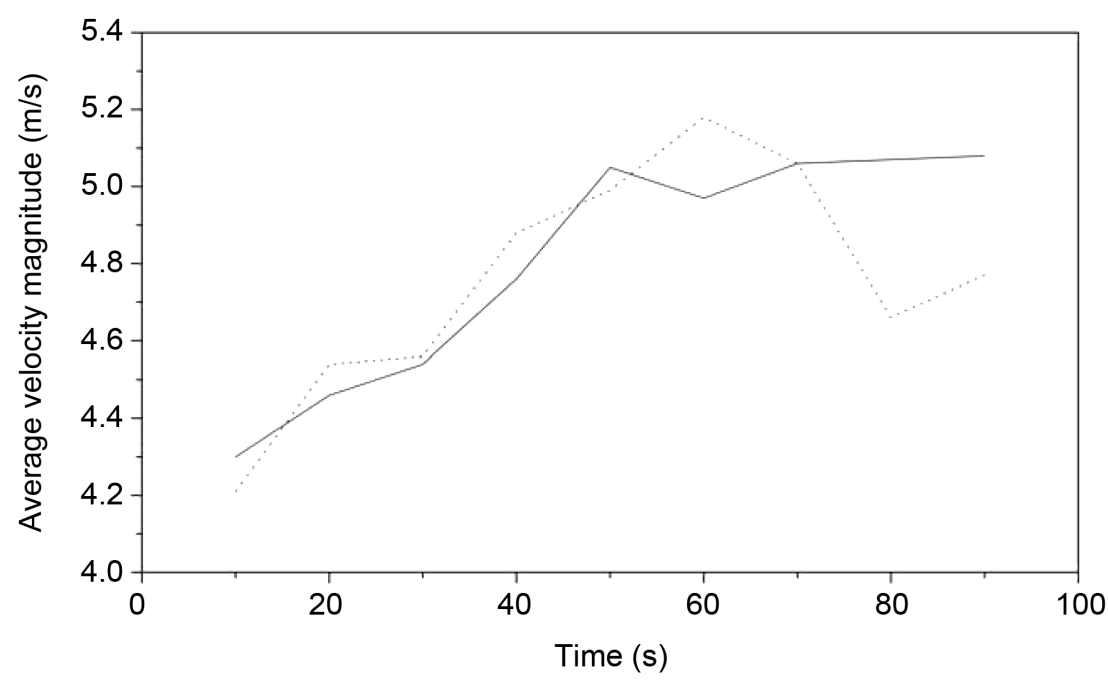

Figure 6. Evolution of the average velocity magnitude in the mold for the cylindrical SEN (solid line) and anchor SEN (dotted line).

velocity magnitude than the cylindrical SEN. This means that the anchor-shaped SEN causes less turbulence in the mold.

\section{Conclusions}

An anchor-shaped Submerged Entry Nozzle design for the continuous casting of steel was proposed in this work. The performance of this nozzle was numerically compared with the performance of a conventional cylindrical nozzle. From the computer results, the following conclusions arise:

1) The cylindrical SEN exhibits the deepest depression of the free surface and the largest velocity vectors in the upper section of the mold.

2) The velocity vectors near the free surface in the vicinity of the SEN are greater for the cylindrical SEN than that corresponding to the anchor-shaped SEN.

3) The chance for the formation of Karman's vortexes and powder entrapment becomes small for the anchor-shaped SEN.

\section{References}

[1] Slezak, W., Korolczuk, M. and Migas, P. (2015) High Temperature Rheometric Measurements of Mold Powder. Archives of Metallurgy and Materials, 60, 289-294. http://dx.doi.org/10.1515/amm-2015-0046

[2] Cramb, A.W. (2003) The Making, Shaping and Treating of Steel. Continuous Casting Volume. AISE Steel Foundation, Pittsburgh.

[3] Thomas, B.G. (2005) Modeling of Continuous-Casting Defects Related to Mold Fluid Flow. The 3 rd International Congress on Science \& Technology of Steelmaking, AIST, Charlotte, 9-12 May 2005, 847-861.

[4] Garcia-Hernandez, S., Morales, R.D., Barreto, J.J. and Morales-Higa, K. (2013) Numerical Optimization of Nozzle Ports to Improve the Flu Dynamics by Controlling Backflow in a Continuous Casting Slab Mold. ISIJ International, 53, 1794-1802.

http://dx.doi.org/10.2355/isijinternational.53.1794 
[5] Iguchi, M., Yoshida, J., Shimizu, T. and Mizuno, Y. (2000) Model Study on the Entrapment of Mold Powder into Molten Steel. ISIJ International, 40, 685-691.

http://dx.doi.org/10.2355/isijinternational.40.685

[6] Iguchi, M. and Ilegbusi, O.J. (2011) Modeling Multiphase Materials Processes: Gas Liquid Systems. Springer, New York. http://dx.doi.org/10.1007/978-1-4419-7479-2

[7] Tsutsumi, K., Watanabe, K., Suzuki, M., Nakada, M. and Shiomi, T. (2004) Effect of Properties of Mold Powder Entrapped in Molten Steel in a Continuous Casting Process. 7 th International Conference on Molten Slags Fluxes and Salts, The South African Institute of Mining and Metallurgy, Johannesburg, 25-28 January 2004, 803-806.

[8] Ueda, Y., Kida, T. and Iguchi, M. (2004) Unsteady Pressure Coefficient around an Elliptic Immersion Nozzle. ISIJ International, 44, 1403-1409.

http://dx.doi.org/10.2355/isijinternational.44.1403

[9] Real, C., Miranda, R., Vilchis, C., Barron, M.A., Hoyos, L. and Gonzalez, J. (2006) Transient Internal Flow Characterization of a Bifurcated Submerged Entry Nozzle. ISIJ International, 46, 1183-1191. http://dx.doi.org/10.2355/isijinternational.46.1183

[10] Liang, Z., Wang, N., Zou, Z. and Yu, A. (2009) Optimization of Submerged Entry Nozzle of Continuous Casting Slab. Proceedings of the 2009 TMS Annual Meeting and Exhibition, San Francisco, 16-19 February, 569-574.

[11] Tsukaguchi, Y., Hayashi, H., Kurimoto, H., Yokoya, S., Marukawa, K. and Tanaka, T. (2010) Development of Swirling-Flow Submerged Entry Nozzle for Slab Casting. ISIJ International, 50, 721-729. http://dx.doi.org/10.2355/isijinternational.50.721

[12] Kuroda, T., Mizobe, A. and Kurisu, J. (2011) Flow Optimization in the Mould by Port Design Improvement of Submerged Entry Nozzle. Proceedings UNITECR 2011 Congress. 12 th Biennial Worldwide Conference on Refractories-Refractories-Technology to Sustain the Global Environment, The American Ceramic Society, 30 October-2 November, Kyoto, 434-437.

[13] Bird, R.B., Stewart, W.E. and Lightfoot, E.N. (2002) Transport Phenomena. 2nd Edition, Wiley, New York.

[14] Thomas, B., Yuan, Q., Sivaramakhrisnan, S., Shi, T., Vanka, S.P. and Assar, M.B. (2001) Comparison of Four Methods to Evaluate Fluid Velocities in a Continuous Slab Casting Mold. ISIJ International, 41, 1262-1271. http://dx.doi.org/10.2355/isijinternational.41.1262

[15] Solorio-Díaz, G., Morales, R.D., Palafox-Ramos, J., García-Demedices, L. and Ramos-Banderas, A. (2004) Analysis of Fluid Flow Turbulence in Tundishes Fed by a Swirling Ladle Shroud. ISIJ International, 44, 1024-1032. http://dx.doi.org/10.2355/isijinternational.44.1024

[16] Hirt, C.W. and Nichols, B.D. (1981) Volume of Fluid (VOF) Method for the Dynamics of Free Boundaries. Journal of Computational Physics, 39, 201-225. http://dx.doi.org/10.1016/0021-9991(81)90145-5

[17] (2003) Fluent 6.1 User's Guide. Lebanon, NH. 
Submit or recommend next manuscript to SCIRP and we will provide best service for you:

Accepting pre-submission inquiries through Email, Facebook, LinkedIn, Twitter, etc. A wide selection of journals (inclusive of 9 subjects, more than 200 journals)

Providing 24-hour high-quality service

User-friendly online submission system

Fair and swift peer-review system

Efficient typesetting and proofreading procedure

Display of the result of downloads and visits, as well as the number of cited articles

Maximum dissemination of your research work

Submit your manuscript at: http://papersubmission.scirp.org/

Or contact ojapps@scirp.org 